\title{
Desenvolvimento sociocognitivo e histórias infantis: subsídios para a prática docente ${ }^{1}$
}

\author{
Marisa Cosenza Rodrigues ${ }^{2}$ \\ Aline Lima Tavares \\ Universidade Federal de Juiz de Fora, Juiz de Fora-MG, Brasil
}

\begin{abstract}
Resumo: Este estudo objetivou avaliar a ocorrência de termos mentais em uma amostra de livros de histórias infantis nacionais bem como a possibilidade de exploração das narrativas pelo modelo do processamento de informação social. Com base em estudos internacionais, 119 livros nacionais dirigidos a pré-escolares foram analisados, considerando-se quatro eixos: (a) palavras e expressões denotando estados mentais; (b) convergência figura/estado mental; (c) presença de ironia situacional e crença falsa; (d) situações oferecedoras de pistas sociais. Os resultados indicaram alto índice de referências a estados mentais (99\%), com predominância de termos cognitivos (42\%) e emocionais (39\%), alta convergência figura/estado mental (74\%), presença de ironia $(21 \%)$, crença falsa $(13,5 \%)$ e expressiva ocorrência de situações, envolvendo pistas sociais internas e externas (98\%). A viabilidade da utilização dos livros infantis como recurso promotor de desenvolvimento sociocognitivo é discutida, apresentando-se subsídios que visam contribuir para a prática docente pré-escolar.
\end{abstract}

Palavras-chave: filosofia da mente, cognição social, educação infantil.

\section{Social cognitive development and childhood tales: tools for teaching}

\begin{abstract}
This study aimed to evaluate the occurrence of mental terms in a sample of Brazilian children's books and the possibility to explore narratives through the process of the social information model. Based on international studies, 119 Brazilian books directed to preschoolers were analyzed considering four axes: (a) words and expressions denoting mental states; (b) convergence figure/mental state; (c) situational irony and false belief and (d) situations giving social tips. The results indicate a high number of references to mental states (99\%), with predominance of cognitive (42\%) and emotional terms (39\%), high convergence figure/mental state (74\%), presence of irony (21\%) and false belief $(13,5 \%)$, and expressive occurrence of situations involving internal and external social tips (98\%). The use of children's books as a resource to promote social-cognitive development is discussed and support is presented with a view to contribute to the practice of preschool teachers.
\end{abstract}

Keywords: philosophy of mind, social cognition, early childhood education.

\section{Desarrollo socio cognitivo e historias infantiles: subsidios para la práctica docente}

\begin{abstract}
Resumen: El objetivo del estudio fue evaluar la incidencia de los términos mentales en una muestra de libros nacionales de cuentos infantiles, así como la posibilidad de exploración de las narrativas por los modelos de procesamiento de información social. Sobre la base de estudios internacionales 119 libros nacionales dirigidos a niños en edad preescolar fueron analizados: se consideraron cuatro ejes: (a) palabras y expresiones que denotan estados mentales (b) convergencia figura/estado mental, (c) presencia de la ironía situacional y falsa creencia (d) situaciones ofrecedoras de pistas sociales. Los resultados mostraron alto índice de referencias a estados mentales (99\%), con predominio de términos cognitivos (42\%) y emocionales (39\%), alta convergencia figura/estado mental (74\%), presencia de ironía (21\%), falsa creencia $(13,5 \%)$ y expresiva aparición de situaciones envolviendo pistas sociales internas y externas (98\%). La viabilidad de la utilización de libros infantiles como recurso promotor del desarrollo socio cognitivo es discutida, presentando subsidios destinados a contribuir con la práctica docente en educación preescolar.
\end{abstract}

Palabras clave: filosofia de la mente, cognición social, educación infantil.

A educação escolar vem sendo convocada a assumir sua função de contribuir para formar a cidadania, incluindo o desenvolvimento de valores, atitudes e habilidades de convivência humana. $\mathrm{O}$ atual referencial curricular nacional para a educação infantil define que essa tem por função criar condições para o desenvolvimento integral de todas as crianças, incluindo o desenvolvimento socioemocional (Ministério da Educação, 1998).

1 As autoras agradecem ao PROPESQ-UFJF pela bolsa concedida à segunda autora. Este texto foi revisado seguindo Acordo Ortográfico da Língua Portuguesa (1990), em vigor a partir de $1^{\circ}$ de janeiro de 2009.

2 Endereço para correspondência:

Profa. Dra. Marisa Cosenza Rodrigues. Universidade Federal de Juiz de Fora. Departamento de Psicologia. Campus Universitário. CEP 36.015400. Juiz de Fora-MG, Brasil.E-mail: rodriguesma@terra.com.br
Como salientam Dessen e Polônia (2007), escola e família constituem contextos fundamentais para a promoção do desenvolvimento humano. Del Prette e Del Prette (2003) observam, no entanto, que dada a alteração da estrutura e funcionamento da família nas últimas décadas, o desenvolvimento das habilidades socioemocionais vem sendo gradualmente deslocado para a escola, que necessita redimensionar-se para enfrentar mais esse desafio. No âmbito do trabalho do psicólogo que atua na educação, o desenvolvimento de competências específicas na infância insere-se no debate, envolvendo a mudança de paradigma que vem deslocando-se de um modelo remediativo, centrado nas dificuldades da criança para outro que visa à promoção de saúde e ao bem-estar psicossocial (Guzzo, 2001; Del Prette \& Del Prette, 2003; Contini, 2000). 
Como ressalta Rodrigues (2004), a necessidade de empreender uma atuação psicoeducacional mais proativa e as demandas emergentes no contexto da educação infantil requerem o desenvolvimento de pesquisas que possam subsidiar estratégias diferenciadas e mais criativas por parte dos psicólogos escolares. Nessa direção, o presente estudo subdividiu-se em dois momentos: uma pesquisa que objetivou investigar uma amostra de 119 livros de histórias infantis com foco na teoria da mente e no processamento de informação social e, subsidiado pelo primeiro, um segundo momento, que buscou estruturar e organizar um trabalho de capacitação para docentes pré-escolares voltado para a promoção do desenvolvimento sociocognitivo na educação infantil.

\section{Teoria da mente}

A teoria da mente é definida como a habilidade de compreender a própria mente e a dos outros. Segundo De Jou e Sperb (1999) e Flavell, Miller e Miller (1999), a capacidade de compreender os estados mentais (sentimentos, desejos, crenças e intenções) é uma das características sociais dos seres humanos, sendo o foco de preocupação de psicólogos desenvolvimentistas e cognitivistas.

Saber em que idade emerge a teoria da mente é um dos problemas que tem ocupado atualmente os pesquisadores. Lourenço (1992) explica que a definição sobre quando a criança possui uma teoria da mente está associada ao que os teóricos entendem como tal. Alguns autores, dentre eles Bretherton e Beeghly (1982), pressupõem que a teoria da mente emerge quando a criança se torna capaz de atribuir estados mentais a si e aos outros, portanto, aos dois ou três anos de idade. De acordo com Santana e Roazzi (2006), há pesquisadores que só consideram que exista uma teoria da mente por volta dos quatro ou cinco anos, quando as crianças se tornam capazes de lidar com a crença falsa.

Os referidos autores, avaliando a compreensão infantil da tarefa da crença falsa, demonstram que uma teoria da mente já está presente em crianças brasileiras a partir dos quatro anos, e que fatores como idade e nível socioeconômico constituem preditores significativos de melhor desempenho nesta tarefa. Outras pesquisas nacionais (Lourenço, 1992; Dias, 1993; Dias, Soares, \& Sá, 1994; Roazzi \& Santana, 1999) também tem contribuído para o debate. Maluf, Deleau, Panciera, Valério e Domingues (2004) observam, no entanto, que há escassez de estudos na literatura nacional com enfoque longitudinal ou de intervenção, que poderiam oferecer maior compreensão do fenômeno e intervenção positiva na realidade individual e social.

Segundo Astington e Pelletier (2000), a expressão "linguagem da mente" envolve o uso explícito de termos mentais para se referir aos estados mentais das pessoas - crenças, desejos, intenções e emoções. Tais termos podem ocorrer em qualquer uma das classes gramaticais: verbos, substantivos, adjetivos ou advérbios.
Bretherton e Beeghly (1982) foram os primeiros a avaliar o uso de termos mentais pelas crianças. Seus resultados apontaram que expressões envolvendo afeto, cognição e termos morais eram menos comuns na fala de crianças entre 28 e 30 meses. Dunn, Bretherton e Munn (1987) verificaram que tanto mães como irmãos mais velhos mencionavam estados de sentimento mais frequentemente com meninas que com meninos; aos 24 meses. Perner, Ruffman e Leekam (1994) evidenciaram que um número maior de irmãos em uma família está relacionado positivamente ao raciocínio da criança em medidas de uma teoria da mente. Furrow, Moore, Davidge e Chiasson (1992) demonstraram que o uso maternal de termos mentais, como "pensam que" e "saiba", com crianças de dois anos, predita seu uso nas crianças de três anos de idade. Os resultados dessas pesquisas evidenciam a importância das oportunidades de acesso às práticas de comunicação verbal durante os primeiros anos de vida.

Cassidy e cols. (1998) ressaltam que a teoria da mente poderia ser influenciada por experiências em que as crianças são expostas ou podem observar o uso de estados mentais. Para os autores, os livros de histórias infantis constituem um recurso útil e valioso. Os resultados obtidos com uma amostra de 317 livros publicados nos Estados Unidos demonstraram que $78 \%$ continham linguagem referente a estados internos e $34 \%$ contemplavam a crença falsa. Dyer, Shatz e Wellman (2000) também realizaram um estudo minucioso analisando 90 livros de histórias infantis com base nas referências voltadas para estados mentais, convergência entre figuras e estados mentais, situações de ironia e presença de crença falsa nas narrativas. Foram consideradas quatro categorias de estados mentais: termos cognitivos, emocionais, de desejo/intenção e avaliação moral/obrigação. Os resultados obtidos foram extremamente favoráveis convergindo com os dados obtidos por Cassidy e cols. (1998) de que os livros infantis estadunidenses estão repletos de termos envolvendo informações relativas aos estados mentais.

Os estudos de Cassidy e cols. (1998) e Dyer e cols. (2000) assinalam a abrangência da área da teoria da mente e o quanto ela vem se ampliando. No contexto nacional, Rodrigues, Oliveira, Rubac e Tavares (2007) inspirados no estudo de Dyer e cols. (2000) investigaram a ocorrência de termos mentais numa amostra de 100 livros de histórias infantis de autores brasileiros. Os resultados indicaram também alto índice de referências aos estados mentais ( $92 \%$ ), alta convergência entre figura e estado mental ( $86 \%$ ) e presença de ironia situacional $(12 \%)$ e crença falsa (11\%). Esses achados corroboraram os das pesquisas internacionais, evidenciando que também os livros de histórias infantis nacionais contêm ampla variedade de termos mentais sendo passíveis de serem explorados, visando ao desenvolvimento sociocognitivo da criança pré-escolar.

\section{Processamento de informação social}

A cognição social, área recente de investigação científica na Psicologia, estuda os processos e mecanismos 
cognitivos envolvidos nos fenômenos psicológicos sociais: considera as pessoas e suas ações como sujeitos ativos, envolvendo o estudo dos processos mentais pelos quais o sujeito conhece o mundo social (Moya e cols., 1992, Rodrigues, 2004, 2005). As reações sociais e afetivo-emocionais que as crianças manifestam dependem, em parte, de como elas pensam. As pesquisas sobre o desenvolvimento sociocognitivo focalizam o conhecimento das crianças e a compreensão do mundo social - das pessoas, incluindo elas mesmas, e o das relações sociais.

A abordagem do processamento de informação social (SIP) oferece um modelo sistemático detalhado de como as crianças processam e interpretam pistas numa situação específica e chegam a uma decisão que é mais ou menos competente do ponto de vista comportamental. Um dos modelos mais estudados foi inicialmente proposto por Dodge (1986), o qual passou, posteriormente, por uma revisão crítica trazendo inovações conceituais (Crick \& Dodge, 1994). Este modelo assume que as crianças, quando deparadas com uma situação social (oferecedora de pistas sociais), tendem a manifestar seis passos mentais antes de exibir um comportamento social: (a) codificação de pistas internas e externas; (b) representação e interpretação dessas pistas; (c) clarificação ou seleção de um objetivo; (d) construção ou acesso à resposta; (e) decisão da resposta; (f) realização do comportamento.

O detalhamento dos passos propostos por Crick e Dodge (1994) aponta uma relação entre particularidades no processamento da informação social e a manifestação de comportamentos agressivos entre crianças e adolescentes. Várias pesquisas corroboram tal relação, como demonstra o estudo meta-analítico realizado por Vasconcelos, Picon, Prochnow e Gauer (2006). Del Prette e Del Prette (2005), com base em vários autores, também salientam que uma das dificuldades da criança agressiva está em interpretar acuradamente as mensagens recebidas, com tendência, em situações ambíguas, a atribuir intenções hostis aos outros. Fazendo um paralelo com a teoria da aprendizagem social, Bear, Webster, Furlong e Rhee (2000) assinalam que as habilidades sociocognitivas, assim como as dificuldades e tendenciosidades são aprendidas por meio de processos como modelagem e reforçamento

Na vertente aplicada, o modelo de Crick e Dodge (1994) foi utilizado no contexto educativo por Teglasi e Rothman (2001), que desenvolveram um programa voltado para a prevenção da agressividade, associando a leitura de histórias ao processamento de informação social com objetivo de ensinar alternativas de ação em situações de conflito. Os resultados indicaram diminuição de comportamentos antissociais e de externalização nos grupos de crianças. Como crianças agressivas têm dificuldade em registrar soluções relevantes para os problemas, além de dificuldade para processar informações relativas às intenções e aos motivos dos outros (Crick \& Dodge, 1994; Vasconcelos e cols., 2006, Elias e Marturano, 2004), as narrativas infantis oferecem um ponto de partida útil para que sejam discutidos e explorados aspectos relevantes deste processamento.

Teglasi e Rothman (2001) apresentam uma descrição de como o programa de histórias, elaborado e implementado, liga os componentes da narrativa aos passos do modelo de Crick e Dodge (1994). As questões propostas pelos autores referidos e que guiam o trabalho com as histórias são: (a) $O$ que está acontecendo? As crianças identificam o problema, fazendo um balanço do que está acontecendo interna e externamente; (b) O que os personagens estão pensando e sentindo? Assim como consideram as circunstâncias externas, as crianças também identificam o problema pela observação do que está ocorrendo no mundo íntimo de cada personagem envolvido na trama; (c) Quais são as intenções e metas dos personagens? Pensamentos e sentimentos dos personagens sobre uma situação particular são discutidos em relação às suas intenções e metas; (d) O que os personagens alcançam com suas ações? Os resultados atuais e prováveis das decisões, planos e ações dos personagens da história são discutidos e explorados em relação às suas metas e intenções prévias; (e) Como os personagens executam e monitoram os próprios comportamentos? Os personagens podem executar a ação intencionada e obter êxito ou serem mal sucedidos na tarefa; (f) Quais as lições aprendidas? Teglasi e Rothman (2001) "assinalam que a solução de problemas efetiva requer a aplicação de lições de vida que são naturalmente aprendidas a partir da experiência" (p. 77, grifos nossos).

$\mathrm{O}$ desenvolvimento de ações preventivas mais inovadoras tem implicações importantes para a prática do psicólogo escolar brasileiro, considerando o atual paradigma de promover saúde e desenvolvimento humano. Entretanto, tal aspecto constitui um dos desafios aos profissionais da área (Guzzo, 2001; Feldman, 1994).

\section{Concepções e prática docente pré-escolar}

A função humanizadora da escola tem sido cada vez mais enfatizada tanto pelos profissionais da área quanto pelas políticas públicas que norteiam a ação desses profissionais. Segundo Coll (1996), a educação promotora de desenvolvimento requer do educador o conhecimento do processo evolutivo das crianças, visando delimitar as possíveis aprendizagens capazes de promover o desenvolvimento.

Astington e Pelletier (2000) afirmam que concepções distintas da mente dos aprendizes mantidas pelos professores levam a diferentes tipos de práticas pedagógicas, assim como o entendimento dos professores sobre a mente é refletido no modo como comunicam sobre ensino e aprendizagem na prática docente. A pesquisa realizada pelos autores indicou que os professores tendem a ajustar o uso da linguagem metacognitiva ao interagirem com crianças.

Rodrigues (2004) investigou concepções de professoras pré-escolares sobre aspectos relacionados ao desenvolvimento da teoria da mente e características sociocognitivas das crianças pré-escolares. Os resultados indicaram que as 
professoras têm um conhecimento simplista e pouco específico em relação às características da criança pré-escolar, percepção também dominante em relação à criança agressiva. As estratégias utilizadas pelas professoras para prevenir o comportamento agressivo da criança pré-escolar mostraram-se pouco consistentes, revelando um plano intuitivo e assistemático de ação pedagógica. No âmbito da atividade de contar histórias, convergindo também com os resultados de Villardi (1999), ficou evidente a falta de direcionamento mais específico com relação às etapas que devem acompanhar a proposição dessa atividade no contexto escolar: não há planejamento e, como decorrência, aspectos do desenvolvimento infantil passíveis de serem trabalhados não são focalizados diretamente.

A utilização dos livros infantis com foco sociocognitivo, pelo caráter inovador e específico, requer uma proposta de capacitação dos educadores que vise contribuir para a compreensão e percepção infantil do mundo social e, no âmbito da prática docente, redimensionar a atividade de contar histórias. Como já afirmado, os objetivos do presente estudo foram: (a) investigar uma amostra de 119 livros de histórias infantis nacionais com foco na linguagem referente aos estados mentais e no processamento de informação social; (b) elaborar um plano de capacitação para professores de educação infantil visando a promoção do desenvolvimento sociocognitivo nesse contexto educativo.

\section{Método}

\section{Instrumentos e Procedimento}

A amostra de 119 livros nacionais para crianças préescolares de 4 a 6 anos foi selecionada visando critérios de qualidade. Foram consultados catálogos de editoras de renome nacional na área da literatura infantil e selecionados livros de autores reconhecidos, premiados e/ou recomendados por instâncias como a Fundação Nacional do Livro InfantoJuvenil.

No que tange à teoria da mente, foi utilizada metodologia semelhante à empregada no estudo anterior de Rodrigues e cols. (2007), que se baseou nas pesquisas de Dyer e cols. (2000). A partir das listas de termos denotando estados mentais gerados tanto por Bretherton e Beeghly (1982), como por Rodrigues e cols. (2007), obteve-se uma listagem de termos mentais que foram subdivididos em quatro categorias: termos cognitivos, emocionais, de desejo e intenção, e avaliação moral/obrigação. Essa listagem categorizada foi utilizada como referência para a codificação dos termos e expressões mentais encontrados nos livros infantis, foram considerados três eixos de análise: (a) codificação e frequência dos termos e expressões mentais encontrados de acordo com as quatro categorias anteriormente citadas; (b) presença de ironia situacional e crença falsa; (c) convergência entre figura e estado mental, gerando-se um instrumento para análise de cada livro.

\section{Análise de dados}

Nos três eixos mencionados, os livros foram analisados pela pesquisadora e por dois juízes. O primeiro eixo (ocorrência de termos e expressões voltados para os estados mentais) foi submetido ao teste de coeficiente de Spearman (Levin, 1987). Os juízes e a pesquisadora, embasados pelo mesmo referencial, discutiram as discordâncias. O segundo eixo de análise (presença de ironia situacional e crença falsa) foi apurado, considerando-se a indicação quanto à presença e à ausência por parte da pesquisadora e dos juízes. Nesse caso, o índice de concordância obtido foi de aproximadamente $95 \%$. O terceiro eixo (convergência entre figura e estado mental) foi analisado, considerando-se três figuras de cada livro (início, meio e fim). Nos livros com narrativas muito curtas ou muito pobres em termos mentais, foi analisado o número de figuras de acordo com o número de páginas contendo termos ou expressões mentais. Utilizou-se como referência nessa análise uma escala variando de 0 a 3 pontos, sendo: 0 - figura nada convergente; 1 - figura pouco convergente; 2 - figura convergente; 3 - expressiva convergência. No último eixo, a análise foi realizada considerando a média aritmética entre as notas atribuídas pelos juízes e a pesquisadora para cada livro analisado. Considerando-se as médias, foram identificados como pouco convergentes livros com notas variando entre 1,1 e 1,5 pontos da escala, como convergentes as notas entre 1,6 e 2,4 e como muito convergentes as avaliações entre 2,5 e 3 .

A análise dos 119 livros de histórias infantis nacionais com foco no processamento de informação social foi realizada tomando como referência o estudo de Teglasi e Rothman (2001), explicitado anteriormente. Foi elaborado um instrumento que visou codificar a presença de pistas sociais internas e/ou externas capazes de responder às questões propostas pelos autores nas narrativas analisadas, que foram consideradas como um tipo de "leitura" possível das situações apresentadas na história. A leitura interna relacionou-se à presença de termos denotando estados mentais dos personagens, enquanto a externa associou-se tanto à presença de balões indicando pensamentos ou falas quanto à análise das expressões faciais dos personagens ou das ações circunstanciais que envolviam determinada questão proposta pelo programa. A primeira questão do modelo ("o que está acontecendo?") constituiu uma exceção: a leitura interna foi codificada quando eram encontradas informações relacionadas às características pessoais ou à personalidade do(s) personagem(s), e a leitura externa mediante a presença de informações relacionadas ao tempo e à localização geográfica. $\mathrm{O}$ instrumento incluiu ainda uma escala geral de avaliação do livro, envolvendo o número de questões propostas no programa de Teglasi e Rothman presentes e passíveis de serem explorados na narrativa. Semelhante à escala utilizada no estudo de Rodrigues e cols. (2007), os livros que contemplaram apenas uma questão do modelo foram descritos como pouco adequados para análise sociocognitiva; aqueles 
que atenderam a duas questões foram considerados com limitado repertório de pistas sociais; os que apresentaram três ou quatro questões do modelo foram avaliados com número relevante de pistas sociais; e as narrativas que contemplaram cinco ou todas as questões do modelo foram avaliadas como ricas do ponto de vista do processamento de informação social. A análise das narrativas baseada em SIP, foi realizada pela pesquisadora e por um juiz independente, sendo posteriormente submetida ao teste de coeficiente de Spearman (Levin, 1987).

O programa de capacitação para docentes pré-escolares foi elaborado com base na literatura pertinente da área incluindo tanto a utilização de recursos visuais (Power Point ou transparências) quanto de material textual.

\section{Resultados e Discussão}

Os resultados obtidos na análise dos livros infantis nacionais quanto à teoria da mente apontaram índice de correlação, pelo teste do coeficiente de Spearman, aproximado de $97 \%$ de concordância. Ou seja, as correlações feitas para categorização envolvendo termos cognitivos, emocionais, desejos/intenções, e avaliação moral/obrigação foram, em sua grande maioria, significantes para o nível de 0,05 , indicando que os juízes emitiram avaliações que não diferiram estatisticamente.

A análise realizada indicou alto índice de referências a estados mentais, 99\% dos livros para crianças de 4 a 6 anos evidenciaram termos denotando estados mentais, 39,5\% da amostra contemplaram as quatro categorias de análise delimitadas (termos emocionais, cognitivos, desejos/intenções, avaliação moral/obrigação), 37\% contemplaram três categorias, $17,5 \%$ contemplaram duas categorias e $6 \%$ contemplaram apenas uma categoria. Ou seja, mais de $75 \%$ dos livros dessa amostra contemplaram de três a quatro categorias de termos mentais. Esses resultados corroboram aqueles obtidos no estudo nacional realizado por Rodrigues e cols. (2007), em que 92\% dos livros analisados evidenciaram termos mentais, como também aqueles encontrados em pesquisas internacionais, como as de Cassidy e cols. (1998) e de Dyer e cols. (2000).

$\mathrm{Na}$ presente amostra, encontrou-se um total de 2.245 termos denotando estados mentais, incluindo-se palavras cognatas (por exemplo, pensar, pensando, pensou). A categoria de termos mais frequente foi a de estados cognitivos, apresentando 937 palavras (42\%), seguida da categoria envolvendo estados emocionais com 880 palavras (39\%), desejo e intenção com 297 (13\%) e avaliação moral e obrigação com apenas 131 palavras (6\%). Agrupando os cognatos, evidenciaram-se 213 tipos diferentes de termos denotando estados mentais; sendo que 95 (43\%) são diferentes daqueles encontrados no estudo anterior de Rodrigues e cols. (2007). Esse dado evidencia a variabilidade de termos nas amostras de livros nacionais.

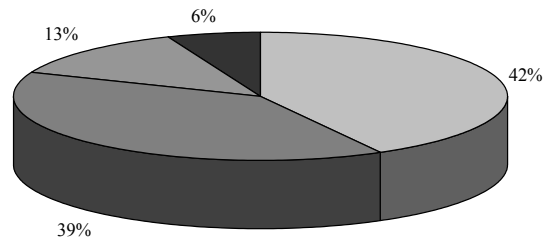

$\square$ cognitivos $\square$ emocionais $\square$ desejo/intenção $\square$ avaliação moral/obrigação

Figura 1. Prevalência de termos mentais na amostra de livros infantis.

Dentre os 937 termos encontrados denotando estados cognitivos (42\% da amostra), vários eram cognatos. Desse modo, na análise final, foram registrados 68 tipos diferentes de palavras (por exemplo: aprender, estudar, imaginar, inventar, lembrar, pensar, saber), sendo que os mais frequentes foram "saber" e "pensar", correspondendo a, respectivamente, $20 \%$ e $15 \%$ dos termos cognitivos. No estudo de Rodrigues e cols. (2007), "saber" também foi o termo mais comum dentre os cognitivos (16\%). Astington e Pelletier (2000), ao avaliarem o uso da linguagem metacognitiva de crianças pré-escolares (situação espontânea de brincadeira na escola), observaram que as crianças produziram pouca fala metacognitiva, mas entre os poucos termos usados, "saber" foi o mais evocado. De acordo com os autores, muito ocasionalmente foram utilizados os termos pensar, lembrar, esquecer e querer dizer. Bretherton e Beeghly (1982), em sua pesquisa envolvendo a fala de crianças com até 28 meses, indicaram "saber" como a palavra cognitiva mais evocada $(66 \%)$. Os autores salientam que os termos cognitivos aparecem mais tardiamente no vocabulário das crianças, na medida em que inferir pensamentos e crenças é mais difícil que percepções, estados fisiológicos e emoções, pois nestes os correlatos comportamentais tendem a ser mais explícitos.

No que se refere aos estados emocionais, foram identificadas 880 palavras (39\%), envolvendo 83 tipos diferentes (por exemplo: aborrecer, alegre, emocionado, feliz, furioso). Nos estudos de Dyer e cols. (2000) e Cassidy e cols. (1998) também se evidenciou expressiva frequência de termos emocionais. A ocorrência significativa de termos voltados para os estados emocionais nas narrativas infantis apresenta-se como importante resultado na medida em que a habilidade que a criança gradualmente adquire de compreender emoções transforma-se em uma ferramenta particularmente poderosa em manejar sentimentos e resolver conflitos interpessoais (Denham, Zoller, \& Couchoud, 1994). A palavra "medo" e seus cognatos (medroso, amedrontado) foram os termos mais frequentes $(12 \%)$. Classificando os termos emocionais como positivos, negativos ou neutros, $25 \%$ denotaram estados positivos (por exemplo: alegre, feliz, divertir, adorar), 58\% estados emocionais negativos (tais como: preocupado, triste, assustado, medo) e 17\% indicaram estados neutros (surpreso, saudade), corroborando resultado obtido por Rodrigues e cols. 
(2007). O estudo de Denham e Couchoud (1990) mostra que crianças pré-escolares têm maior habilidade para reconhecer e nomear emoções positivas do que negativas.

No estudo já citado de Rodrigues e cols. (2007), os termos emocionais foram os mais frequentes $(41 \%)$, seguidos pelos termos cognitivos (39\%). Observa-se que no presente estudo os resultados obtidos são inversos a estes: os termos cognitivos correspondem a $42 \%$ da amostra enquanto os emocionais a $39 \%$. Dado que a variação percentual entre termos cognitivos e emocionais foi discreta nos dois estudos (apenas $2 \%$ ), pode-se considerar que os resultados foram semelhantes em ambos, ou seja, predominaram termos cognitivos e emocionais. Esses resultados convergem com os obtidos por Dyer e cols. (2000), nos quais também se evidenciou expressiva frequência de termos emocionais e cognitivos.

Quanto aos termos denotando desejo ou intenção (13\%), incorporando-se os cognatos, foram identificados 22 tipos diferentes de palavras (por exemplo: querer, propósito, pedir, vontade, desejo). Dentre esses, "querer" predominou com $43 \%$. No estudo de Dyer e cols. (2000), cinco tipos de palavras se referiam a desejo e intenção - esperar, precisar, querer, desejar e gostaria. Frye (1991) salienta que o desenvolvimento infantil da habilidade para agir intencionalmente constitui um precursor evolutivo da teoria da mente. Feinfield, Lee, Flavell, Green e Flavell (1999) demonstram que aos três anos e meio ou quatro anos de idade as crianças começam a desenvolver uma concepção diferenciada da intenção, sugerindo a adequação da utilização desses termos nas narrativas infantis.

Do total de 2.245 termos denotando estados mentais, somente 131 termos (6\%) denotavam avaliação moral e obrigação. Agrupando os termos semelhantes foram encontrados 41 tipos diferentes de palavras, tais como: (in)justiça, obedecer, mandar, "ter que", ordenar. Nessa categoria, o termo mais encontrado foi "ladrão" com 19 referências (14,5\%). Observa-se que Dyer e cols. (2000) encontraram um percentual bem mais expressivo com relação à essa categoria de termos, , perfazendo $60 \%$ da amostra de livros infantis estadunidenses.

No que se refere à convergência entre figura e estado mental, 74\% do total de livros apresentaram-se como convergentes ou totalmente convergentes, sendo que os livros que atenderam a esta última categoria corresponderam a $30 \%$ da amostra, $24 \%$ dos livros analisados foram considerados pouco convergentes e apenas $2 \%$ ( 3 livros) não evidenciaram grau de convergência. Esses resultados corroboram os do estudo anterior de Rodrigues e cols. (2007), no qual também foi encontrado um alto índice de convergência entre figura e estado mental ( $86 \%$ ). No entanto, divergem, em parte, daqueles obtidos por Dyer e cols. (2000), os quais indicaram que sozinhas as figuras falharam para representar de modo independente conceitos de estado mental expressados no texto.
A crença falsa foi evidenciada em 16 dos 119 livros $(13,5 \%)$; estando presente nos seguintes contextos: (a) o envolvimento do disfarce conjugado com a pretensão de enganar o outro (2 livros); (b) percepção equivocada da realidade (10 livros); (c) carência de informações (4 livros). Esses dados, associados aos de Rodrigues e cols. (2007), em que a crença falsa foi evidenciada também em apenas $11 \%$ da amostra, indicam que situações envolvendo a crença falsa de uma forma mais explícita são pouco utilizadas no contexto da literatura infantil nacional.

No que se refere à ironia, em 25 dos 119 livros analisados $(21 \%)$ foi constatada sua ocorrência. A presença da ironia foi identificada em dois diferentes contextos: (a) quando a informação era explícita, restringindo-se aos eventos apresentados ao longo do texto; (b) quando a ironia só poderia ser interpretada por meio de um conhecimento prévio do leitor. Nesse segundo caso, por exemplo, a compreensão da ironia no livro "O caçador valente" envolvia conhecimento sobre hábitos alimentares. Como a ironia, segundo Dyer e cols. (2000), encoraja o leitor a uma perspectiva além da que é imediatamente dada, fornecendo informações sobre a mente em diversos assuntos, os resultados pouco expressivos obtidos com essa amostra de livros, assim como os de Rodrigues e cols. (2007), em que a ironia foi evidenciada em apenas $12 \%$ da amostra, sugerem que esse aspecto poderia ser mais explorado pelos autores nacionais.

Os resultados obtidos na análise dos livros infantis pelo processamento de informação social indicaram índice de correlação pelo teste do coeficiente de Spearman aproximado de $94 \%$. As correlações feitas para a categorização em relação às categorias de leitura interna, externa e avaliação do livro com base na escala do estudo anterior de Rodrigues e cols. (2007) foram, em sua grande maioria, significantes para o nível de 0,05 .

A análise dos livros com base no processamento de informação social apresentou resultados bastante satisfatórios, $98 \%$ da amostra evidenciaram presença de pistas sociais externas respondendo às questões propostas por Teglasi e Rothman (2001) e $97,5 \%$ registraram a presença de pistas sociais internas. De acordo com a escala de avaliação utilizada, a maior parte das narrativas (53\%) foi considerada com relevante repertório de pistas sociais, por ser possível explorar três ou quatro componentes do programa, 39 livros (33\%) tiveram suas narrativas avaliadas como ricas do ponto de vista do processamento de informação social, por possibilitarem a prática com livros considerando cinco ou seis questões do programa desenvolvido por Teglasi e Rothman. Desse modo, 86\% dos livros analisados possuem narrativas possíveis de serem utilizados como estratégias sociocognitivas que visam maximizar o processamento de informação social. Somente 15 livros (12\%) foram avaliados com escasso ou limitado repertório de pistas sociais, contemplando uma ou duas das perguntas propostas, e apenas $2 \%$ da amostra foi considerada inadequada com base no modelo SIP, por não responder a nenhum dos 
componentes do programa proposto por Teglasi e Rothman. Os livros dessa amostra podem, pois, ser explorados do ponto de vista do processamento de informação social, já que suas narrativas, em sua maioria, respondem às questões do programa proposto por Teglasi e Rothman, tanto por pistas sociais internas, indicando estados mentais, quanto externas, refletindo percepções externas dessas pistas.

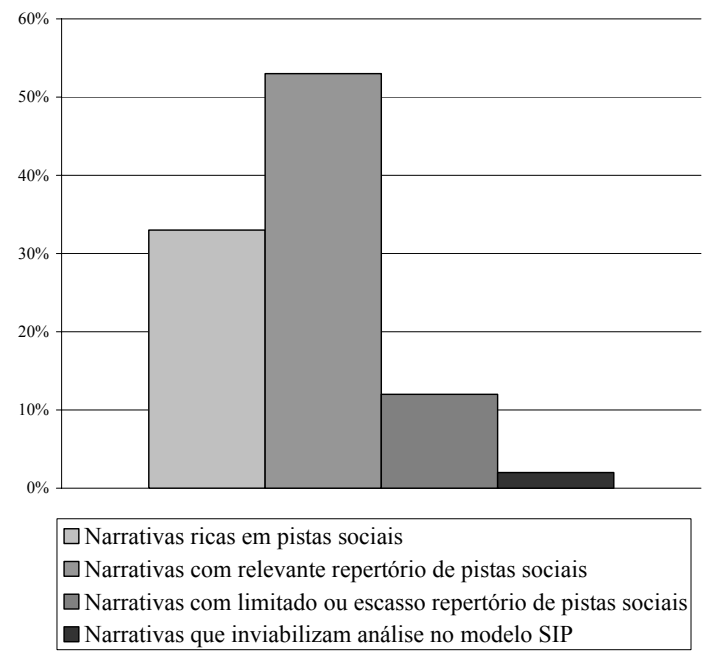

Figura 2. Avaliação das narrativas com base no programa de Teglasi e Rothman.

Os resultados dessa pesquisa corroboram os encontrados no estudo anterior de Rodrigues e cols. (2007), na qual expressiva parte dos livros analisados (75\%) evidenciou narrativas com elevado repertório de pistas sociais. Nesse contexto, os livros de histórias infantis apresentam-se como recursos potenciais e acessíveis de trabalho para o psicólogo escolar brasileiro, na medida em que possibilitam a análise das situações de conflito apresentadas na narrativa, proporcionando alternativas de ação à violência e à coerção, uma vez que contribuem para o aperfeiçoamento do processamento de informação social.

A primeira questão do programa (o que está acontecendo?) foi evidenciada em $73 \%$ dos livros. A leitura externa das pistas sociais, aquela indicando a presença de informações relacionadas ao tempo e à localização geográfica, foi mais frequente que a leitura interna, que se referia às características pessoais dos personagens. A segunda questão (o que os personagens estão pensando e sentindo?) foi evidenciada praticamente na totalidade da amostra (97\%), sendo identificada alta frequência de pistas sociais tanto externas $(80 \%)$, relativas às expressões faciais dos personagens ou presença de balões de pensamento, quanto internas $(91 \%)$, relativas à presença de termos mentais. A terceira questão do programa (quais as intenções e metas dos personagens?) foi evidenciada em $80 \%$ da amostra, e também nesse componente a leitura interna foi identificada na grande maioria dos casos (76\%). É importante destacar a elevada presença de pistas sociais, indicando uma leitura interna das situações no segundo e terceiro componentes do programa. Tais resultados convergem com a elevada quantidade de termos mentais cognitivos, emocionais e de desejo e intenção encontrados nesta amostra de livros nacionais.

A quarta questão (o que os personagens alcançam com suas ações?) e a quinta (como os personagens executam e monitoram seus comportamentos?) foram contempladas, em respectivamente, $55 \%$ e $65 \%$ da amostra. Nesses dois componentes, a leitura externa das pistas sociais foi utilizada com frequência muito superior à das pistas internas. Isso possivelmente ocorreu por ser mais simples registrar o resultado de ações planejadas ou o monitoramento de comportamentos (esconder-se para verificar uma situação, por exemplo) por meio das ilustrações do que pela presença de termos mentais. A elevada presença de pistas sociais externas encontradas na análise desses componentes do programa indica que as ilustrações presentes nas narrativas dos livros nacionais podem ser exploradas ao longo da narrativa, como foi sugerido por Teglasi e Rothman (2001), além de reforçar o dado relativo à alta convergência entre figura e estado mental. O sexto componente (quais as lições aprendidas pelos personagens?) foi contemplado em $10 \%$ da amostra, ou seja, somente essa porcentagem dos livros analisados apresentou explicitamente uma lição que poderia ser explorada diretamente. Em grande parte dos livros, essa mensagem aparece implícita ao final da história, considerando a leitura interna das pistas sociais. O registro desse sexto componente, quando explicitado nas histórias infantis, foi semelhante para as leituras externas $(8 \%)$ e internas $(6 \%)$.

Ainda que no estudo de Rodrigues e cols. (2007) a presença das questões propostas no modelo de Teglasi e Rothman (2001) não tenha sido analisada do ponto de vista de uma leitura interna ou externa das pistas sociais, os resultados relativos à presença dos componentes do programa na narrativa são semelhantes, o que corrobora e amplia os resultados encontrados no presente estudo. Conjuntamente, os dois estudos envolveram um total de 219 livros infantis nacionais. Ressalta-se que esta perspectiva cognitivo-social de trabalho com os livros infantis já vem sendo explorada pela autora e outras colaboradoras, numa proposta de extensão universitária, no CPA/UFJF com crianças agressivas, com resultados positivos no que se refere à minimização do comportamento agressivo (Oliveira, Rodrigues, Abreu, \& Carvalho, 2007).

Os resultados apresentados nessa pesquisa forneceram subsídios para a estruturação e organização de um trabalho de capacitação com professoras pré-escolares, sobretudo em escolas que apresentam em seu quadro professoras de literatura infantil. Nesse sentido, Del Prette e Del Prette (2003) salientam que os professores tendem a valorizar a promoção do desenvolvimento interpessoal, mas apresentam dificuldade em promovê-lo, tanto como coadjuvante de questões acadêmicas, quanto como objetivo adicional, evidenciando um papel pouco explorado das condições de ensino na prática do professor em sala de aula. A proposta de capacitação docente elaborada, desdobramento da pesquisa empírica, 
dividiu-se em fundamentação teórica e parte prática, tendo sido programada para ocorrer em 13 encontros com duração aproximada de 90 minutos cada. Na primeira etapa (teórica) a proposta focaliza: uma atualização de informações quanto às características sociocognitivas das crianças pré-escolares (capacidade de compreender crenças, emoções, intenções e desejos), informações sobre a área da teoria da mente e sobre o processamento de informação social. Na segunda etapa (prática), serão oferecidos exemplos de exploração do livro infantil no cotidiano da sala de aula, de forma a potencializar o trabalho relacionando o livro, a teoria da mente e o processamento de informação social. Como complemento prático, as próprias professoras farão uma análise individual de livros infantis previamente selecionados visando fomentar a habilidade docente de: identificar termos mentais nas narrativas, avaliando a possibilidade de exploração desses termos na fala com os alunos, relacionar termos mentais às expressões faciais dos personagens e explorar situações na narrativa oferecedoras de pistas sociais.

\section{Considerações finais}

Os resultados da presente pesquisa evidenciam que o livro infantil constitui uma ferramenta valiosa que pode ser utilizada para promover o desenvolvimento sociocognitivo. Evidenciou-se que as narrativas estão repletas de termos mentais (sobretudo termos cognitivos e emocionais), como também apresentam um repertório expressivo de pistas externas e internas e outros componentes sociocognitivos que podem ser explorados pelo professor em sala de aula. Os subsídios empíricos aqui reportados reforçam a crença de que é possível redimensionar a atividade de contar histórias e, por meio desta atividade cotidiana, favorecer a linguagem mental e a compreensão infantil a respeito de si e do mundo social. Nesse sentido, a intencionalidade educativa assume papel de relevância na direção de ampliar, do ponto qualitativo (compreensão), a gama de termos mentais bem como aprimorar o processamento de informação social a partir de um trabalho docente que envolva, de forma mais sistemática, análise prévia e mediação dialogada da narrativa junto às crianças.

Considerando que são necessárias outras pesquisas que ampliem a análise dos livros infantis nacionais, e não pretendendo esgotar discussões em torno do trabalho docente com a literatura infantil, destaca-se que os resultados fornecem substrato psicoeducacional para o trabalho de psicólogos que atuam na educação infantil, sensíveis à necessidade de empreender uma atuação mais proativa e menos reativa neste contexto de desenvolvimento.

\section{Referências}

Astington, J. D., \& Pelletier, J. (2000). A linguagem da mente: Seu papel no ensino e na aprendizagem. In D. R. Oslon \& N. Torrance (Orgs.), Educação e desenvolvimento humano (7a ed., pp. 489-510). Porto Alegre: Artmed.
Bear, G. G., Webste, S., Furlong, M. J., \& Rhee, S. (2000). Preventing aggression e violence. In K. M. Minke \& G. G. Bear (Eds.), Preventing school problems - promoting school succes: Strategies and programs that work (pp. 1-69). Washington, DC: National Association of School Psychologist.

Bretherton, I., \& Beeghly, Y. M. (1982). Talking about internal states: The acquisition of an explicity theory of mind. Developmental Psychology, 18, 906-921.

Cassidy, K. W., Ball, L. V., Rourke, M. T., Wermer, R. S., Feeny, N., Chu, J. Y., Lutz, D. J., \& Perkins, A. (1998). Theory of mind concepts in children's literature. Applied Psycholinguistics, 19, 463-470.

Coll, C. (1996). Desenvolvimento psicológico e processos educacionais. In C. Coll, J. Pallacios, \& A. Marchesi (Orgs.), Desenvolvimento psicológico e educação: Psicologia da educação (Vol. 2, pp. 325-339). Porto Alegre: Artes Médicas.

Contini, M. L. J. (2000). Discutindo o conceito de promoção de saúde no trabalho do psicólogo que atua na educação. Psicologia: Ciência e Profissão, 20(2), 46-59.

Crick, N. R., \& Dodge, K. A. (1994). A review and reformulation of social information-processing mechanisms in children's social adjustment. Psychological Bulletin, 115, 74-101.

Denham, S. A., \& Couchoud, E. A. (1990). Young preschooler's understanding of emotions. Child Study Journal, 20, 171-192.

Denham, S. A., Zoller, D., \& Couchoud, E. A. (1994). Socialization of preschooler's emotion understanding. Developmental Psychology, 30, 928-936.

De Jou, G. I., \& Sperb, T. M. (1999). Teoria da mente, diferentes abordagens. Psicologia: Reflexão e Crítica, 12, 287-306.

Del Prette, Z. A. P., \& Del Prette, A. (2003). Aprendizagem socioemocional na infância e prevenção da violência: Questões conceituais e metodologia de intervenção. In Z. A. P. Del Prette \& A. Del Prette (Orgs.), Habilidades sociais, desenvolvimento e aprendizagem (pp. 83-127). Campinas, SP: Alínea.

Del Prette, Z. A. P., \& Del Prette, A. (2005). Psicologia das habilidades sociais na infância: Teoria e prática. Petrópolis, RJ: Vozes.

Dessen, M. A., \& Polônia, A. C. (2007). A família e a escola como contextos de desenvolvimento humano. Paideia (Ribeirão Preto), 17, 21-32.

Dias, M. G. B. B.(1993). Odesenvolvimento do conhecimento da criança sobre a mente. Psicologia: Teoria e Pesquisa, 9, 587-600.

Dias, M. G., Soares, G. B., \& Sá, T. P. (1994). Conhecimento sobre a mente e compreensão sobre as intenções do experimentador. Psicologia: Teoria e Pesquisa, 10, 221-229.

Dodge, K. A. (1986). A social information processing model of social competence in children. In M. Perlmutter (Ed.), The Minnsesota Symposium on Child Psychology (pp. 77-125). Hillsdale, MI: Erlbaum. 
Dunn, J., Bretherton, I., \& Munn, P. (1987). Conversations about feeling states between mothers and their young children. Developmental Psychology, 23, 132-139.

Dyer, J. R., Shatz, M., \& Wellman, H. M. (2000). Young children's storybooks as a source of mental state information. Cognitive Development, 15, 17-37.

Elias, L. C., \& Marturano, E. M. (2004). Habilidades de solução de problemas interpessoais e prevenção dos problemas de comportamento escolares. In E. M. Marturano, M. B. Linhares, \& S. R. Laureiro (Orgs.), Vulnerabilidade e proteção: Indicadores na trajetória do desenvolvimento escolar (pp. 197-215). São Paulo: Casa do Psicólogo.

Feinfield, K. A., Lee, P. P., Flavell, E. R, Green, F. L., \& Flavell, J. H. (1999). Young children's understanding of intention. Cognitive Development, 14, 463-486.

Feldman, N. (2004). De prevención a promoción: Un desafio latinoamericano. Congresso Nacional de Psicologia Escolar, 2, 85-88.

Flavell, J. H., Miller, P. H., \& Miller, A. S. (1999). Desenvolvimento cognitivo. Porto Alegre: Artmed.

Frye, D. (1991). The origins of intention in infancy. In D. Frye \& C. Moore (Eds.), Children's theories of mind: Mental states and social understanding (pp. 15-38). Hillsdale, MI: Erlbaum.

Furrow, D., Moore, C., Davidge, J., \& Chiasson, L. (1992). Mental terms in mothers' and children's speech: Similarities and relationships. Journal of Child Language, 19, 617-931.

Guzzo, R. S. L. (2001). Saúde psicológica, sucesso escolar e eficácia da escola: Desafios do novo milênio para a psicologia escolar. In Z. A. Del Prette (Org.), Psicologia escolar e educacional: Saúde e qualidade de vida (pp. 25-42). Campinas, SP: Alínea.

Levin, J. (1987). Estatística aplicada a ciências humanas. São Paulo: Harbra.

Lourenço, O. (1992). Teorias da mente na criança e o desenvolvimento de crenças falsas: Falsas de quem? Análise Psicológica, 4, 431-42.

Maluf, M. R., Deleau, M., Panciera, S. D., Valério, A., \& Domingues, S. F. (2004). A teoria da mente: Mais um passo na compreensão da mente das crianças. In $\mathrm{M}$. R. Maluf (Org.), Psicologia educacional: Questões contemporâneas (pp. 53-86). São Paulo: Casa do Psicólogo.

Ministério da Educação. Secretaria de Educação Fundamental. (1998). Referencial Curricular Nacional para a Educação Infantil. Brasília: MEC.

Moya, M., Rebolloso, E., Fernández Dols, J. M., Huici, C., Marques, J., Paez, D., \& Pérez, J. A. (1992). Estructuras y procesos de la cognicion social. In J. F. Morales (Org.), Psicologia social (pp. 124-148). Buenos Aires: Mc Graw-Hill.
Oliveira, J. S., Rodrigues, M. C., Abreu, C. S., \& Carvalho, C. G. (2007). Prevenção da agressividade na educação infantil. Congresso Nacional de Psicologia Escolar e Educacional, 8. Recuperado em 15 setembro 2007, de http://www.viiiconpe.psc.br/

Perner, J., Ruffman, T., \& Leekam, S. R. (1994). Theory of mind is contagious: You catch it from your sibs. Child Development, 65, 1228-1238.

Roazzi, A., \& Santana, S. M. (1999). Teoria da mente: Efeito da idade, do sexo e do uso de atores animados e inanimados na inferência de estados mentais. Psicologia: Reflexão e Crítica, 12, 307-330.

Rodrigues, M. C. (2004). Concepções docentes pré-escolares sobre teorias da mente e sociocognitivas aplicadas: Histórias infantis. Tese de doutorado não-publicada, Pontifícia Universidade Católica de Campinas, Campinas, SP.

Rodrigues, M. C. (2005). Prevenção na escola: Um enfoque cognitivo-social. In M. M. Mota (Org.), Psicologia: Interfaces com a educação e a saúde (pp. 11-30). Juiz de Fora, MG: EdUFJF.

Rodrigues, M. C., Oliveira, P. A., Rubac, J., \& Tavares, A. L. (2007). Literatura infantil e desenvolvimento sociocognitivo: Contribuições da teoria da mente e do processamento de informação social. Psicologia Escolar e Educacional, 11, 77-88.

Santana, S. M., \& Roazzi, A. (2006). Cognição social em crianças: Descobrindo a influência de crenças falsas e emoções no comportamento humano. Psicologia: Reflexão e Crítica, 19, 1-8

Teglasi, H., \& Rothman, L. (2001). Stories: A classroombased program to reduce aggressive behavior. Journal of School Psychology, 39, 71-94.

Vasconcelos, S. J., Picon, P., Prochnow, L. P., \& Gauer, G. J. (2006). O processamento das informações sociais em crianças e adolescentes agressivos. Estudos de Psicologia (Natal), 11, 275-279.

Villardi, R. (1999). Ensinando a gostar de ler e formando leitores para a vida inteira. Rio de Janeiro: Dunya.

Marisa Cosenza Rodrigues é Professora Adjunta do Departamento de Psicologia do Instituto de Ciências Humanas e Letras da Universidade Federal de Juiz de Fora.

Aline Lima Tavares é graduada em Psicologia pelo Instituto de Ciências Humanas e Letras da Universidade Federal de Juiz de Fora, psicóloga da Prefeitura Municipal de Niterói-RJ.

Recebido: 11/07/2008

$1^{a}$ revisão: $29 / 01 / 2009$

$2^{a}$ revisão: $24 / 07 / 2009$

Aceite final: 10/07/2009 